\title{
Concept, Models and Methods of Sustainability in Croatian Companies
}

\author{
Tihomir OPETUK, Hrvoje CAJNER, Goran ĐUKIĆ, Davor KOLAR
}

\begin{abstract}
Due to high greenhouse gas GHG emissions which will have great negative impacts on the environment in the following decades we will be facing significant climate changes. Because of the before mentioned fact many standards, directives, concepts, methods and models dealing with sustainability have appeared. This paper presents the survey which has been carried out in Croatia business sector in view of current state and trends, barriers and drivers of sustainability. First part of the paper consists of overview of Life Cycle Assessment, Product Lifecycle Management, Product Life Cycle Management, Life Cycle Management and Green Supply Chain Management terms. Second part of the paper presents the survey which is carried out in Croatia business sector regarding current state and trends of sustainability. The results show how well the companies are familiarized with and implement standards, directives, concepts, methods and models connected with sustainability.
\end{abstract}

Keywords: concepts, methods and models; directives and standards; performance analysis; survey; sustainability

\section{INTRODUCTION}

Today, one of the most threatening environmental issues is the increased greenhouse gas (GHG) emissions in the atmosphere. This will have strong negative impacts on the environment in the following decades [1].

The main effect will be on the natural and human systems [2]. The GHG emissions can also be limiting factor for the economic growth. This is especially present in the countries which are in transition process [3]. The protocol that was adopted in 2012 at the UN Climate Change Conference COP18 CMP8 in Doha is one of the reasons for that. The leaders of world industrial sector agreed to reduce the emissions of the GHG approximately $18 \%$ below 1990 levels by 2013-2020 [4].

Having on mind the protocol, the overall environmental awareness is increasing all over the world and the Green Supply Chain Management (GSCM) appeared as one of the most valuable concepts. The GSCM integrates environmental thinking into supply chain management [5]. This is done by many greening elements within the concept. Greening elements are aimed at reduction of materials, waste, energy, pollution and emissions. They also promote the usage of recyclable materials and renewable energy sources in different segments of supply chain. There are many examples from industry that confirm that this is a concept that is getting more and more popular in the world. There is also significant interest of academic community that could be seen through published research papers, research projects and doctoral theses.

Fig. 1 presents three main drivers for implementing the greening process into their corporation and company $[6,7$, 8]. There are also many concepts, methods and models which are dealing with ecology and which have the same goal - greener processes of supply chain/production. When we consider cleaner production, greener supply chains, we can find a lot of various concepts, methods and models that appear, but the literature is not always consistent in the terminology [8].

Therefore, first part of this paper is an overview of Life Cycle Assessment (LCA), Product Lifecycle Management (PLM), Product Life Cycle Management (PLCM), Life Cycle Management (LCM) and Green Supply Chain Management (GSCM) terms. This overview also aims at identifying interrelations, similarities and differences among LCA, PLM, PLCM, LCM and GSCM concepts, methods and models. Also, Sustainable Supply Chain Management (SSCM), Environmental Supply Chain Management (ESCM), Green Logistics (GL), Sustainable Logistics (SL), Environmental Logistics (EL), Clean Logistics (CL) and Green Production (GP), Sustainable Production (SP), Environmental Production (EP), Clean Production (CP) are connected to sustainability so they are included into the research. Many concepts of sustainable development are closely correlated with the standards and directives, so they are also added into the research. They are presented in Fig. 2.

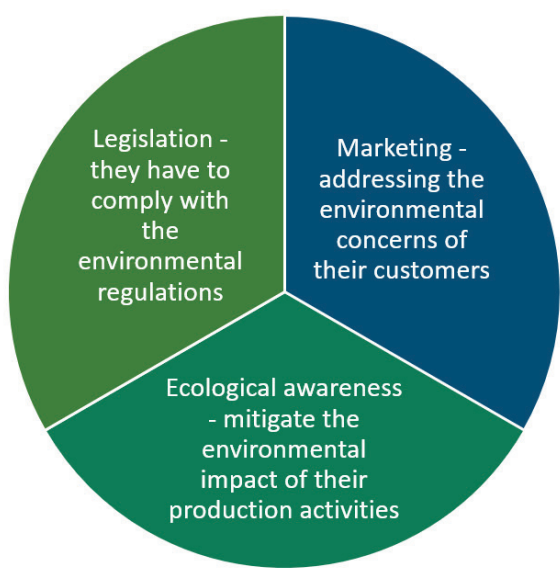

Figure 1 Three main drivers for implementing the greening process

By reviewing the literature, immense number of papers can be found that address one or more concepts, methods and models [8]. As mentioned, the aim of this paper is to investigate interrelation between LCA, PLM/PLCM/LCM and GSCM that appears in scientific literature. Hence, focus is on researches that are mentioning LCA, PLM/PLCM/LCM and GSCM as a group. Consequently, that will help to define the difference and similarity between above mentioned concepts, methods and models.

The survey carried out in Croatia business sector in view of current state and trends of sustainability presents the second part of the paper. The results show how well companies are familiarized and are implementing the above mentioned standards, directives, concepts, methods and models. The idea is to find out which standards and 
directives can help with the implementation of the concepts, methods and models. Likewise, concepts, methods and models that can help with the implementation of standards and directives can be identified.

Standards
- ISO 9001 Quality management systems - Requirements
- ISO 14001 Environmental management systems - Requirements with
guidance for use
- ISO 14040 Environmental management - Life cycle assessment -
Principles and framework
- ISO 14051 Environmental management - Material flow cost accounting -
General framework
- ISO 14062 Environmental management - Integrating environmental
aspects into product design and development
- ISO 14064 Greenhouse gases - part 1, 2, 3
- ISO 26000 Guidance on social responsibility
- ISO 50001 Energy management systems - Requirements with guidance
for use
- OHSAS 18001 Occupational health and safety management systems

\section{Directives}

- WEEE Waste Electrical and Electronic Equipment Directive,

- RoHS Directive on the restriction of the use of certain Hazardous

substances in electrical and electronic equipment

- IPP Integrated Product Policy

- EuP Energy using Products directive

- ELV End of Life Vehicles directive

- EPA Environmental Protection Act

- PPW Packaging and Packaging Waste directive

- EMAS Eco-Management and Audit Scheme directive

- VOC Volatile Organic Compounds directive

- ED Eco-design directive

Figure 2 Standards and directives connected with the sustainable development

\section{LITERATURE REVIEW}

Current state of field of sustainability is done by studying papers collected from Science Direct and Scopus.

Most of the relevant journals in the field of industrial engineering, energy, ecology and production like Journal of Industrial Ecology, Journal of Advanced Research, European Journal of Operational Research, International Journal of Life Cycle Assessment, International Journal of Logistics Systems and Management, Journal of Cleaner Production, Journal of Ecology, Journal of Applied Ecology have been investigated.

Currently, authors of this paper have put focus only on papers dealing with (GSCM or SSCM or ESCM) and (LCA) and (PLM or PLCM or LCM) at the same time, although there are more concepts that are engaged in sustainability as the main topic.

Altogether 130 papers were analysed, but further analysis has shown that some of them exist in both databases. Finally, 7 case studies explaining implementation of concept, method or model, 29 review papers and 67 scientific papers enter the next step of the analysis. In this step, scientific papers were divided in two groups. Total of 37 papers propose a conceptual model, framework or some guidelines, while 30 papers define mathematical models, respectively. Since most of the papers deal with conceptual models, frameworks and guidelines, authors prepared brief overviews of some.

Bai and Sarkis [9] define a model for the selection of sustainable suppliers depending on different factors. Former models use economic and environmental factors for vendor evaluation, while authors also add social factors such as human rights violations, child exploitation, and irresponsible investments.

Chen et al. [10] proposed a model for the selection of suitable sustainability strategy by using analytical network process. Additionally, they also prepared literature review related to green strategies within green supply chains such as (green design, green procurement, green production and green marketing).

In [11], Despeisse et al. investigated sustainable production-related written papers for the following terms: green manufacturing, clean production, sustainable production, eco-conscious production, industrial ecology, etc. They defined production model driven by industrial ecology and based on the energy, material and waste flow and aimed at better understanding of the interactions between manufacturing operations, assets, suppliers and environment.

Duflou et al. [12] provide a systematic overview of the state, methods and techniques in order to increase the efficiency and utilization of energy and resource use in discrete production. Possible savings are considered at several levels: one machine in the process, several machines in the process, the whole factory, more factories and the entire supply chain.

Hassini et al. [13] proposed a systematic framework that can be used as introduction to sustainable supply chain management. Their research also includes reviews of the case study papers written between 2000 and 2010. Additionally, they described the process of implementation of SSCM in the Canadian energetic company. Importance of defining and measuring the performance of SSCM's through implementation-specific indicators has been highlighted. As stated, measuring and addressing the developed KPI-s leads to the possibility of creation of new initiatives.

Pigosso et al. [14] present various eco-design methods that focus on the integration of different end-of-life product strategies. Special attention is given to re-production which they believe to have an increasing international importance in reducing the life-span of the product.

Seuring [15] analysed written papers proposing mathematical models of GSCM or SCM in the past 15 years. In [16], the same author deals with the similarities and differences between the integrated supply chain management, industrial symbiosis, LCM and supply chain management.

Sarkis in his paper [17] provides a framework that helps to understand the difference between the GSCM and other green strategies, such as network management of supply chains, sustainability of supply and demand, or corporate social responsibility network, ESCM, green purchasing and green procurement, environmental purchase, sustainable supply chain and EL and GL. Various flows of resources such as flow of materials, services, finance, information and waste as well as boundaries and limitations related to green supply chain are defined. The author stated that main boundaries of green supply chain are information, legal, cultural, 
organizational, technological, political, economic, temporary and proximal (physical and geographical location), respectively.

Holos et al. [18] research is based on analysis of papers related to the sustainable supply chains, finally leading to the proposal of a triple bottom line approach that involves economic, environmental and social component. Western Europe-based sustainable supply chains have been found and investigated and results have shown that sustained cooperation of suppliers, in relation to the strategicoriented procurement has a positive impact on green and social procurement while on the other hand social practices and sustainable cooperation between suppliers do not have a significant impact on the performance of the enterprise. Additionally, authors conclude that green practices have a positive impact on reducing the cost and performance of the company.

Mollenkopf et al [19] researched the literature to find the link between the green strategy, the lean strategy and the global supply chain strategy. They are trying to find out how to implement these strategies in order to develop a research program for future decision-making when implementing the strategy.

Liu et al. [20] investigated more than 100 papers dealing with sustainable concepts, methods and models. Their research is based on the impact of the LCA, multicriteria decision-making, sustainable design and SP to sustainable supply chains. According to them, there are three trends related to sustainability: sustainability has moved to the entire LCA from the evaluation of a single phase, sustainability has moved from single criteria decision-making to the multiple criteria decision-making and sustainability has become an integrated systematic methodology compared to the previous stand-alone approach.

Bi [21] did a research of the production models and sustainability within them. Based on analysis of the production needs, differences between models and limitations and bottlenecks of the model, author defines 6R sustainable supply chain model consisting of remanufacture, redesign, recover, reuse, recycle and reduce.

Shan-Ping and Chang-Lin [22] in their work propose a three-layer model for assessing the green production performance. This is to identify the key factors for successful implementation of such a system. The first (upper) layer of the model includes three dimensions: the green construction, the green production process and the green packaging. The middle layer includes 10 strategic subjects, while the bottom (bottom) layer includes 74 rating factors. The weights of each layer were obtained by means of questionnaires and calculated using the Analytic Hierarchy Process (AHP) method.

Govindan et al. [23] search for the literature related to articles written between January 2007 and March 2013. They searched articles related with environmental, legal, social and economic factors, reverse logistics and closed loop supply

Devika et al. [24] developed a model for a network of supply chains based on a closed loop. In their work, they used the Triple Bottom Line (3BL) approach, which minimizes total costs and impact on the environment, and maximizes the social benefit. Mixed Integer Linear Programming (MILP) is proposed for modelling.

Leigh and $\mathrm{Li}$ [25] explore the relationship between industrial ecology, industrial symbiosis and SSCM. The authors argue that industrial ecology and industrial symbiosis are not used when introducing SSCM into companies. Based on the literature review and collaboration with large distribution companies in the UK, they create a conceptual framework that considers industrial ecology and industrial symbiosis when introducing SSCM within the enterprise.

Kannan et al. [26] in the paper suggest, with the help of Technique for Order Preference by Similarity to Ideal Solution (TOPSIS), a framework for selecting green suppliers for Brazilian companies dealing with the production of electronic equipment. The results of the research indicate that there are four dominant criteria for the introduction of GSCM: commitment of top management to GSCM; the design of a product that reduces, reuses, recycles and returns materials, components or energy; compliance with legislation, environmental regulations and auditing programs; and product design that avoids or reduces the use of toxic and hazardous materials.

According to the author's knowledge and review of literature, it can be concluded that this kind of research has not yet been done. This survey and its analysis can help companies to implement sustainability to their business process. Also, this then can help to find and to determine the decision-making model for implementation of new concept, models, methods, directive and standards.

\section{LIFE CYCLE ASSESSMENT, PRODUCT LIFECYCLE MANAGEMENT, PRODUCT LIFE CYCLE MANAGEMENT, LIFE CYCLE MANAGEMENT}

LCA as a methodology refers to focusing on environmental impacts of the products. The methodology was developed in the USA beverage company applying the life cycle perspective studying different types of containers [27].

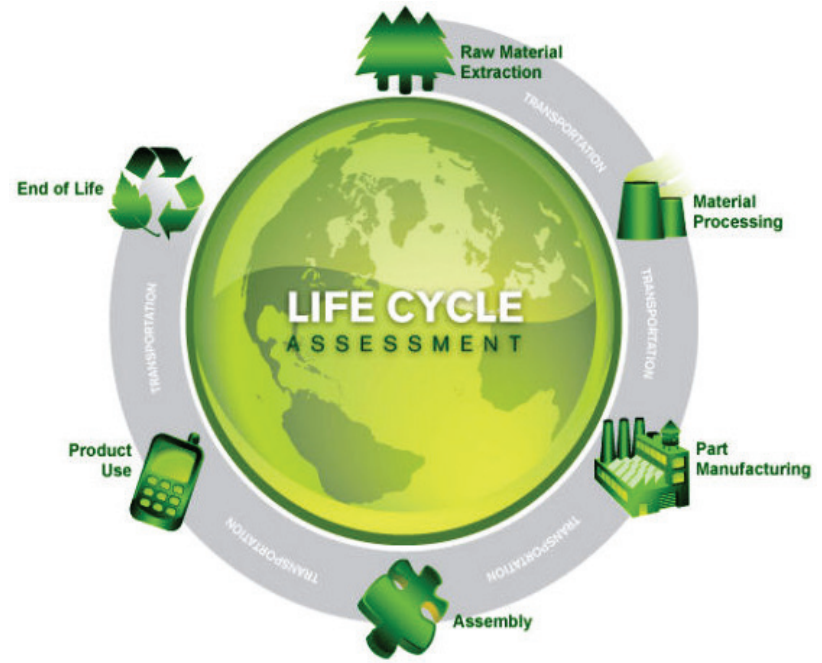

Figure 3 LCA method (Source: [28])

The ISO 14040 norm is defining the LCA as a "compilation and evaluation of the product inputs, outputs and potential environmental impacts of the product system 
throughout its life cycle" (Fig. 3). LCA is a tool for analysing the environmental footprint of the product in every stage of life, from the extraction of the resources, production of materials, production of the parts and final product, use of product to the final disposal [29]. Taking into account the definition it is obvious that there are some differences when comparing to PLM, PLCM and LCM.

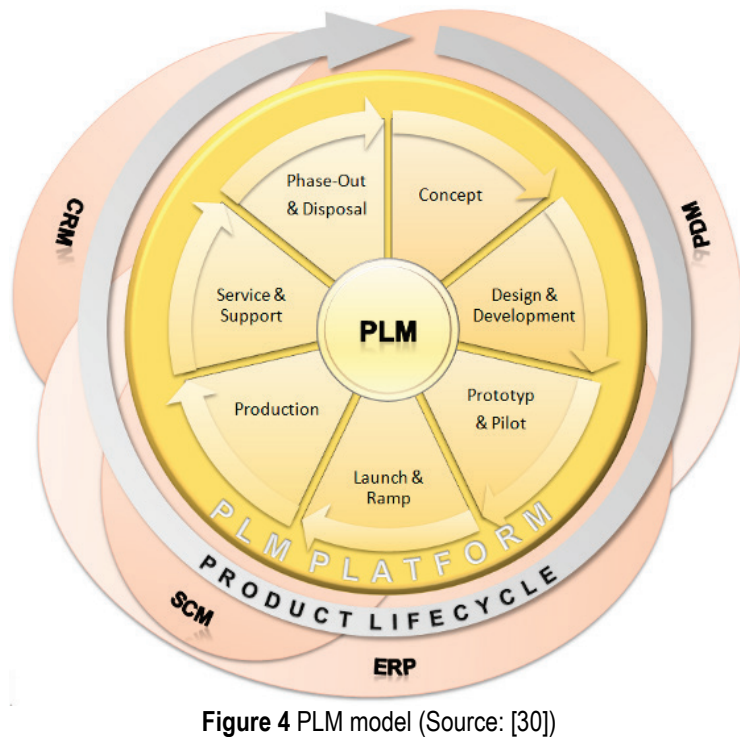

Thus, PLM is the process of managing the lifecycle of the product from the first stage of the design through manufacturing, use and final disposal (Fig. 4). This should not be mistaken by PLCM which refers to the management of the life of the product in the business market with respect to the sales measures and costs [31]. Thus PLM describes the life cycle throughout engineering perspective. The definition of the LCM is an integrated model which refers to management of the life cycle of products or services to achieve more sustainable consumption and production patterns [32].

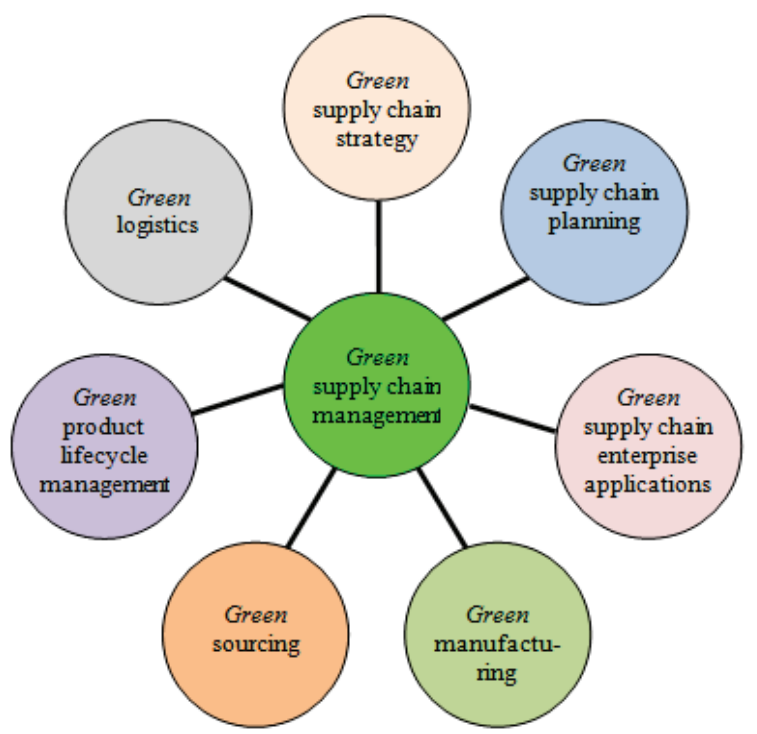

Figure 5 Elements of GSCM (Source: [7])

\section{GREEN SUPPLY CHAIN MANAGEMENT}

According to the literature the definition of the Supply Chain Management SCM can be interpreted as a planning and management of all activities involved in sourcing and procurement, collaboration and all logistics management activities [33]. It involves the cooperation and coordination with partners such as suppliers, intermediaries, service providers and customers. Basically, Supply Chain Management integrates supply and demand management within and between the companies and if that makes the process "green" then it can be defined as Green Supply Chain Management - GSCM (Fig. 5). Therefore, GSCM is a way of green thinking across all segments of the basic groups of activities such as procurement, operations and logistics [7] (Fig. 6).

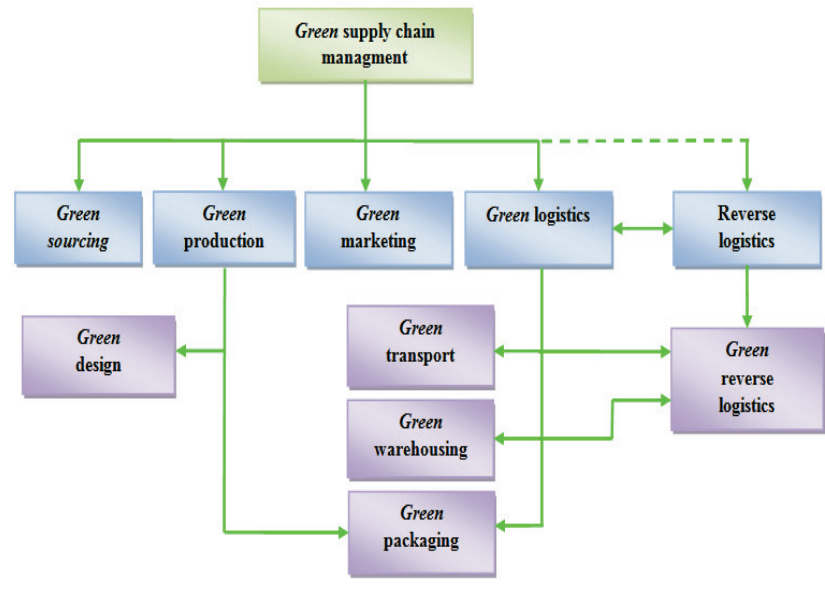

Figure 6 Greening diagram (Source: [7])

\section{DESIGN OF THE SURVEYS}

The LCA, PLM, PLCM, LCM, GSCM and other above mentioned concept, methods and model related to sustainability are relatively new in Croatia. Because of that their state and trends are not correctly known and that was one of the reasons for this kind of surveys. The survey was carried out in Croatian business sector. The assumption is that the respondents answer the survey objectively regardless of the job position. Furthermore, the candidates for the survey were chosen in the way that the representative sample is obtained. The structure of the survey is shown in Fig. 7.

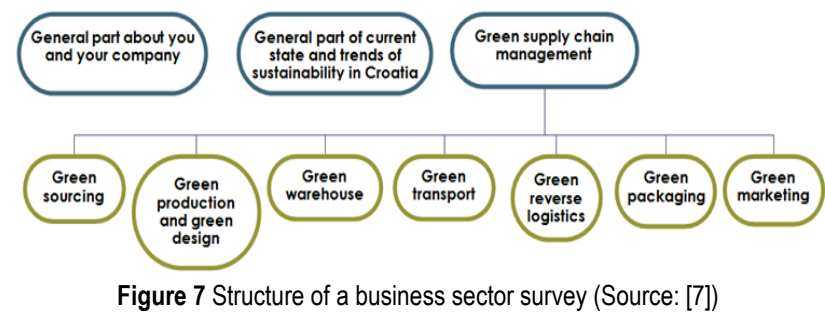

The first part of the survey includes general questions about the examinee and company he works in. The second part of the survey is designed to get insight to the knowledge of sustainable concepts, methods, models, standards and directives and if there are some which are implemented or are in the stage of implementation. The third part includes questions regarding the drivers, barriers, 
activities and benefits of implementing the GSCM. Other parts of the survey represent activities within GSCM. Total survey has 57 questions.

In this paper only, the results of the second part of the survey (general part of current state and trends of sustainability in Croatia) are presented. Survey was conducted in on line form using LimeSurvey software.

\section{RESULTS OF THE SURVEY}

The invitation for the survey was sent to $3257 \mathrm{big}$, medium and small companies with different categories of the business. Survey was carried out in three independent parts. Results are shown for the second part of the survey. 102 complete answers for the second part of the survey were received. Performance analysis of the survey was made using software Statistica 12.

Results of the survey [7] are presented in these three parts:

- Standards,

- Directives,

- Concepts, methods and models.

\subsection{Standards}

Figures below show the level of familiarity with the standards (Fig. 8) and the level of implementation of the standards (Fig. 9).

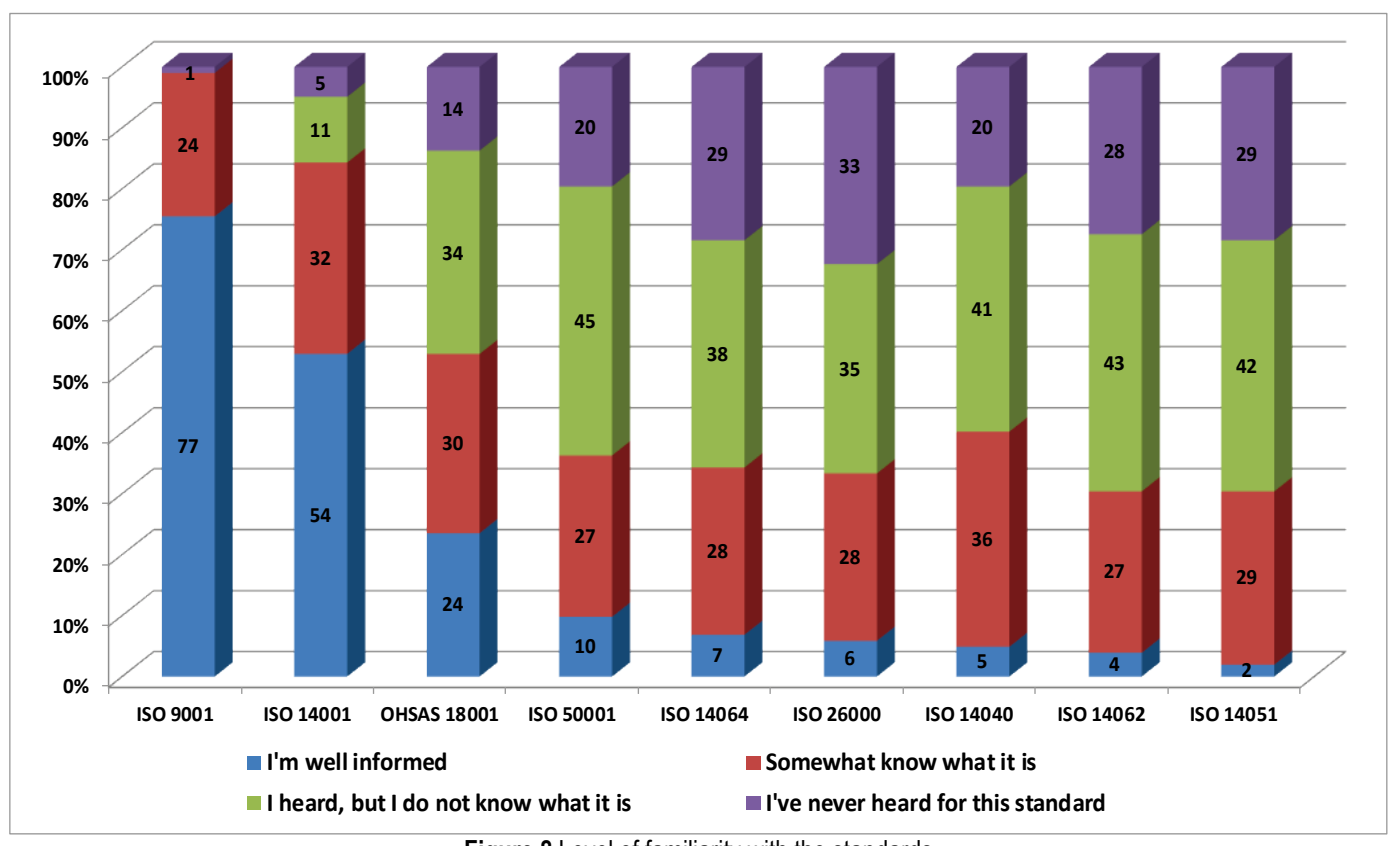

Figure 8 Level of familiarity with the standards

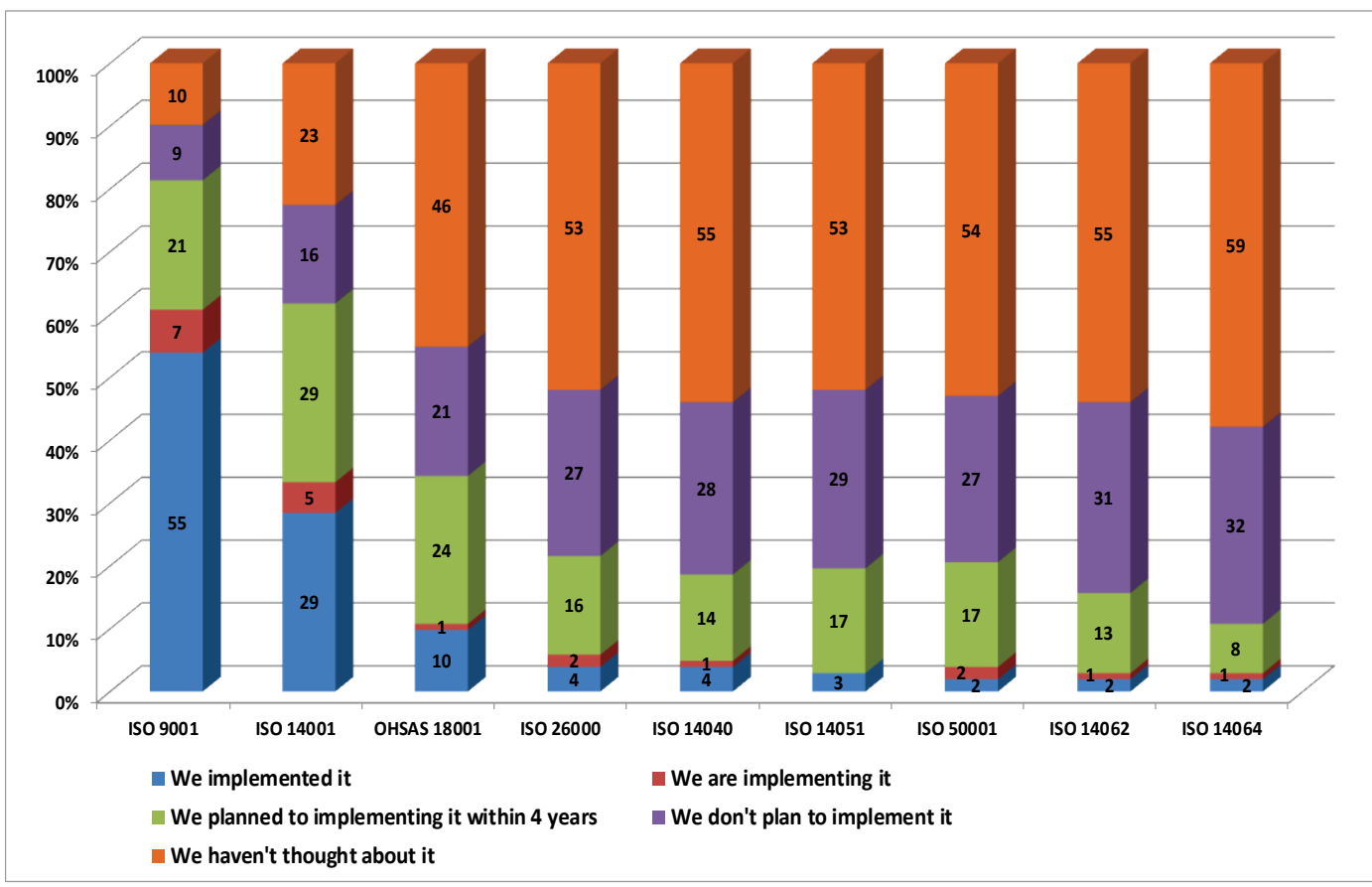

Figure 9 Level of current state of implementation of the standards 
Regarding Fig. 8, which shows the level of the knowledge of the above mentioned standards, it is obvious that companies are most familiar with the ISO 9001, ISO 14001 and OHSAS 18001 standards. Likewise, these standards are the standards which are mostly implemented within the surveyed companies (Fig. 9). Conducted $\chi^{2}$-test taking into account familiarity with the standards and level of implementation of the standards shows a significant difference between individual standards. That confirms the hypothesis that the companies are more or less familiar with some standards. These results are surprising because ISO 9001, ISO 14001 and OHSAS 18001 standards are the world's most widely recognized standards. Also many companies request from the suppliers to have those standards so they can prove their quality, environmental care, and employee safety and safety at work. It can be concluded that these are the "most popular" standards in
Croatia and the standards that are most likely to be implemented into the companies.

The results of correlation coefficient test are shown in the following tables:

- Tab. 1: Connection of level of implementation of the standards and level of familiarity with the directives, concepts, models and methods,

- Tab. 2: Connection of level of implementation of the standards and level of implementation of the directives, concepts, models and methods.

In the correlation test, the sign indicates the direction of the connection (positive or negative), while the absolute value indicates the strength of the correlation. The closer it is to 1,00 , the stronger the correlation. The value higher than 0,20 indicates that there is a statistically significant correlation.

Table 1 Correlation of level of implementation of the standards and level of familiarity with the directives, concepts, models and methods

\begin{tabular}{|c|c|c|c|c|c|c|c|c|c|c|c|}
\hline \multirow{2}{*}{$\begin{array}{l}\text { Level of } \\
\text { implementation of } \\
\text { the standards }\end{array}$} & \multicolumn{11}{|c|}{ Level of familiarity with the directives, concepts, models and methods } \\
\hline & WEEE & RoHS & PPW & EMAS & EPA & ED & LCA & $\begin{array}{c}\text { GSCM/S } \\
\mathrm{SCM} / \mathrm{ES} \\
\mathrm{CM}\end{array}$ & $\begin{array}{l}\text { PLM/ } \\
\text { LCM }\end{array}$ & $\begin{array}{c}\mathrm{GL} / \mathrm{SL} / \mathrm{EL} \\
/ \mathrm{CL}\end{array}$ & $\begin{array}{c}\mathrm{GP} / \mathrm{SP} / \mathrm{E} \\
\mathrm{P} / \\
\mathrm{CP}\end{array}$ \\
\hline ISO 9001 & 0,1461 & 0,0525 & 0,1192 & 0,0692 & 0,1325 & $-0,0194$ & 0,1167 & 0,0857 & 0,1085 & 0,1068 & 0,1420 \\
\hline ISO 14001 & 0,2432 & 0,2220 & 0,3101 & 0,2068 & 0,3112 & 0,1858 & 0,3307 & 0,2577 & 0,3065 & 0,2999 & 0,3155 \\
\hline OHSAS 18001 & 0,1402 & 0,1075 & 0,1118 & 0,1298 & 0,2985 & 0,0294 & 0,3019 & 0,3582 & 0,2433 & 0,3044 & 0,2724 \\
\hline ISO 14040 & 0,0653 & 0,1329 & 0,0785 & 0,0746 & 0,1690 & 0,0295 & 0,2289 & 0,2839 & 0,2688 & 0,2951 & 0,2478 \\
\hline ISO 26000 & 0,0800 & 0,1670 & 0,2067 & 0,2265 & 0,2924 & 0,1344 & 0,2679 & 0,3117 & 0,2773 & 0,3264 & 0,3231 \\
\hline
\end{tabular}

Table 2 Correlation of level of implementation of the standards and level of familiarity with the directives, concepts, models and methods

\begin{tabular}{|c|c|c|c|c|c|c|c|c|c|c|c|}
\hline \multirow{2}{*}{$\begin{array}{l}\text { Level of } \\
\text { implementation of } \\
\text { the standards }\end{array}$} & \multicolumn{11}{|c|}{ Level of implementation of the directives, concepts, models and methods } \\
\hline & WEEE & RoHS & PPW & EMAS & EPA & ED & LCA & $\begin{array}{c}\text { GSCM/S } \\
\text { SCM/ES } \\
\text { CM }\end{array}$ & $\begin{array}{l}\text { PLM/ } \\
\text { LCM }\end{array}$ & $\begin{array}{c}\mathrm{GL} / \mathrm{SL} / \mathrm{EL} \\
/ \mathrm{CL}\end{array}$ & $\begin{array}{c}\mathrm{GP} / \mathrm{SP} / \mathrm{E} \\
\mathrm{P} / \\
\mathrm{CP}\end{array}$ \\
\hline ISO 9001 & 0,1324 & 0,0005 & 0,0724 & 0,1153 & 0,1649 & 0,0176 & 0,2198 & 0,2433 & 0,2289 & 0,2287 & 0,1890 \\
\hline ISO 14001 & 0,2704 & 0,1444 & 0,1380 & 0,1641 & 0,2895 & 0,0959 & 0,2085 & 0,2432 & 0,1867 & 0,2453 & 0,1966 \\
\hline OHSAS 18001 & 0,1749 & 0,1028 & 0,2754 & 0,2373 & 0,4488 & 0,2674 & 0,4312 & 0,4371 & 0,4518 & 0,5037 & 0,4238 \\
\hline ISO 14040 & 0,2473 & 0,2533 & 0,2115 & 0,3291 & 0,3437 & 0,2841 & 0,6329 & 0,4808 & 0,5725 & 0,5355 & 0,5090 \\
\hline ISO 26000 & 0,2388 & 0,1968 & 0,2690 & 0,2938 & 0,3916 & 0,3329 & 0,6157 & 0,5298 & 0,5585 & 0,6412 & 0,5860 \\
\hline
\end{tabular}

Tabs. 1 and 2 show that the level of implementation of the ISO 9001 standard does not affect the level of familiarity with the directives, concepts, models and methods. In addition, this standard has a positive effect on the level of implementation of some concepts, models and methods. On the other hand, ISO 14001 has a positive impact on the level of familiarity and level of implementation of some of the directives, concepts, models and methods. The OHSAS 18001, ISO 14040 and ISO 26000 standards have a positive impact on the level of familiarity with concepts, models and methods, and have a positive impact on the level of implementation of the directives, concepts, models and methods. It should be noted here that the level of implementation of the ISO 14001 standard has a positive impact on the level of implementation or compliance of the EPA (Environmental Protection Act). Of course, this relation is valid vice versa, i.e. that the EPA has a positive impact on the level of implementation of the ISO 14001 standard. This can be interpreted in the way that companies that implemented the ISO 14001 standard can more easily comply with and reach the goals set by EPA. There is also a statistically significant and high positive correlation between the ISO 14040 standard and the LCA method and the PLM/LCM concept. This connection is not surprising because the ISO 14040 standard applies to the LCA method, and the LCA method is often used as a tool within PLM and LCM.

As a general conclusion it can be concluded that the level of implementation of the above mentioned standards (except ISO 9001 standard) positively affects the level of familiarity and level of implementation of the directives, concepts, models and methods. This means that companies that have implemented the above mentioned standards can easier and sooner implement or apply the above mentioned directives, concepts, models and methods.

\subsection{Directives}

Fig. 10 shows the level of familiarity with the directive while Fig. 11 shows the level of implementation of the directive. From Figs. 10 and 11 it can be seen that there are directives with which companies are more or less familiar or they are more or less being introduced or implemented.

This hypothesis is also confirmed by performing the $\chi^{2}$ test. The companies are more familiarized with the directives, WEEE, EPA, RoHS and PPW, but on the other hand, companies are mostly introduced or implementing (applying) WEEE, RoHS, EPA and PPW directives. It should be noted that companies are obliged to comply with certain directives, depending on type of production, 
location of the production plant and market where they operate.

The question is why the ignorance occurs. The main reason is that the Republic of Croatia has recently entered the EU and not all companies are familiarized with the directives and are applying them; furthermore, that vast number of small and medium-sized businesses have difficulty dealing with directives and laws. The reason for this is lack of the employees and employee competences related to knowledge of environmental regulations (directives and laws). Companies may be punished by competent institutions for non-compliance with the directives and law.

The results of correlation coefficient test are shown in the following tables:

- Tab. 3: Connection of level of implementation of the directive and level of familiarity with the concepts, models and methods,

- Tab. 4: Connection of level of implementation of the directives and level of implementation of the concepts, models and methods.

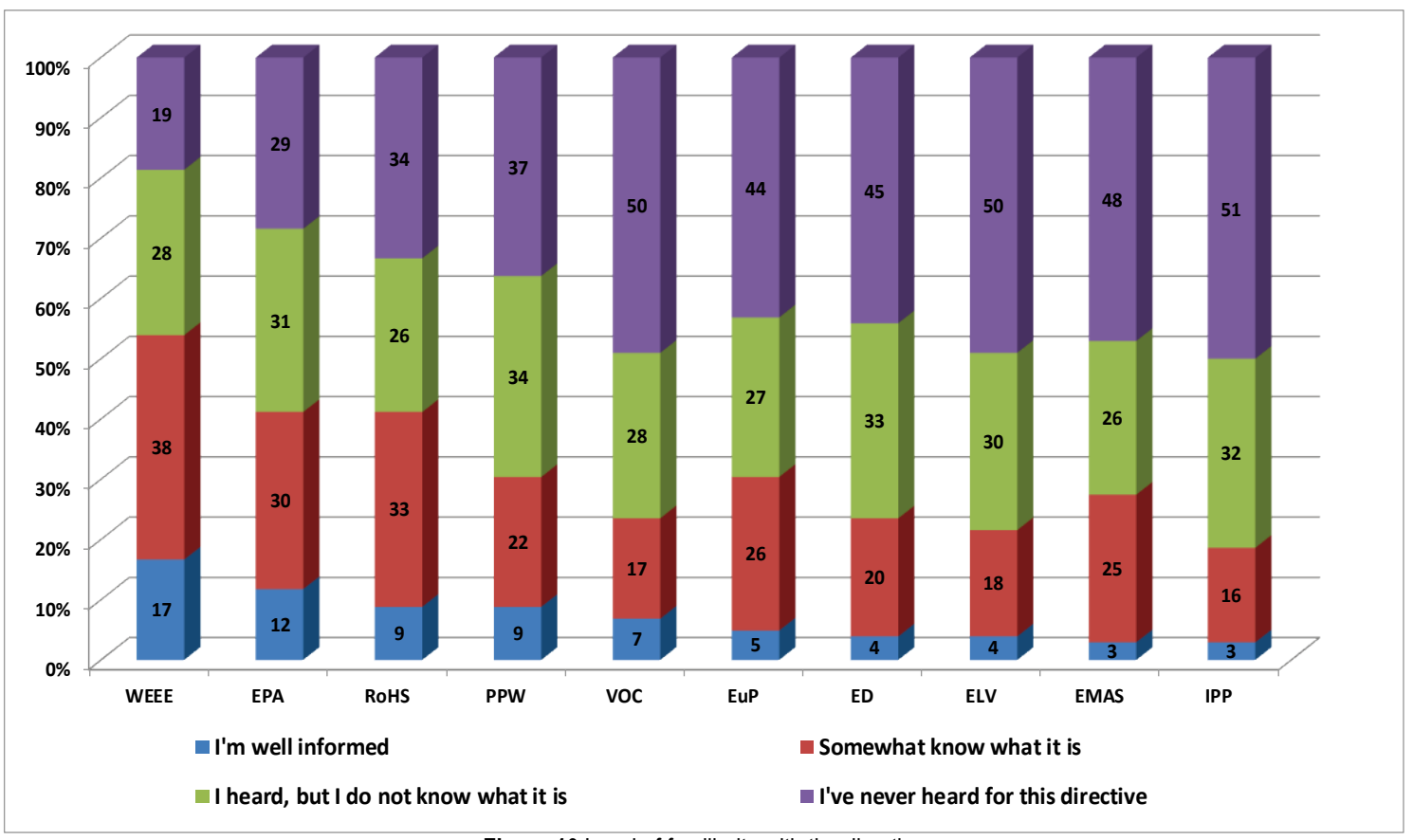

Figure 10 Level of familiarity with the directive

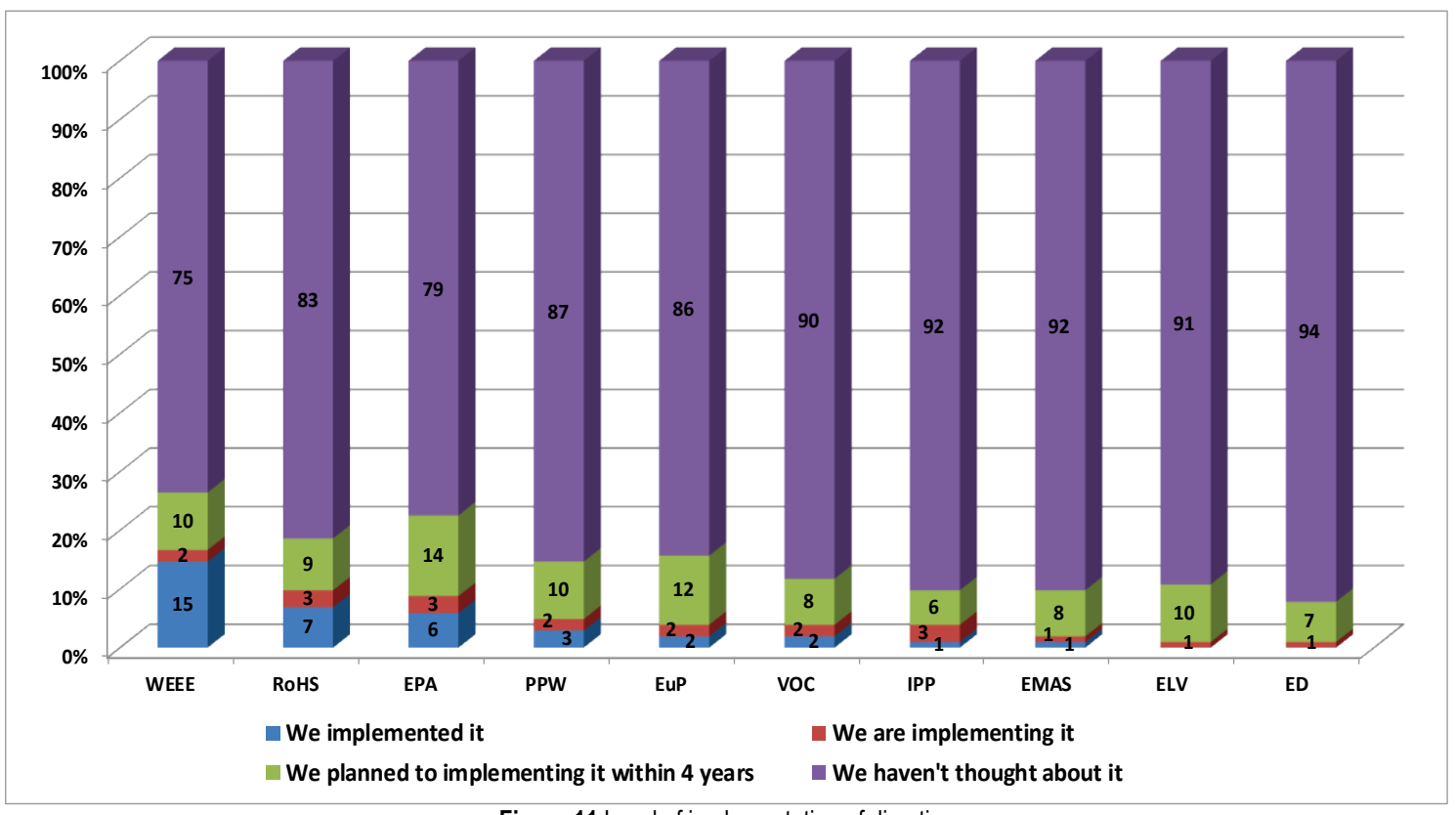

Figure 11 Level of implementation of directive

As a general conclusion, based on Tabs. 3 and 4, it can be concluded that the level of implementation of the directives is positively correlated with the level of familiarity and level of implementation of the concepts, models and methods. This means that companies that have introduced or implemented (applied) some of the above mentioned directives can easier and sooner implement some of the above mentioned concepts, models and methods. For the authors of this paper this is not a surprise, because the directives only define the terms and limits that 
companies need to accomplish, but not the way how to do so. For this reason, companies are turning to sustainable concepts, models and methods to achieve this goal.

Table 3 Correlation of level of implementation of the directives and level of familiarity with the concepts, models and methods

\begin{tabular}{|c|c|c|c|c|c|}
\hline \multirow{2}{*}{$\begin{array}{c}\text { Level of implementation } \\
\text { of the directives }\end{array}$} & \multicolumn{5}{|c|}{ Level of familiarity with the concepts, models and methods } \\
\cline { 2 - 6 } & LCA & GSCM/SSCM/ESCM & PLM/LCM & GL/SL/EL/CL & GP/SP/EP/CP \\
\hline WEEE & 0,2155 & 0,2994 & 0,3238 & 0,3339 & 0,3395 \\
\hline RoHS & 0,2989 & 0,2509 & 0,3423 & 0,3669 & 0,2776 \\
\hline PPW & 0,2497 & 0,2606 & 0,2522 & 0,2956 & 0,2268 \\
\hline EMAS & 0,1416 & 0,2094 & 0,1809 & 0,2568 & 0,3006 \\
\hline EPA & 0,3163 & 0,2383 & 0,3500 & 0,2875 & 0,3675 \\
\hline ED & 0,1997 & 0,1843 & 0,2261 & 0,3194 & 0,2321 \\
\hline
\end{tabular}

Table 4 Correlation of level of implementation of the directives and level of implementation of the concepts, models and methods

\begin{tabular}{|c|c|c|c|c|c|}
\hline \multirow{2}{*}{$\begin{array}{c}\text { Level of implementation } \\
\text { of the directives }\end{array}$} & \multicolumn{5}{|c|}{ Level of implementation of the concepts, models and methods } \\
\cline { 2 - 6 } & LCA & GSCM/SSCM/ESCM & PLM/LCM & GL/SL/EL/CL & GP/SP/EP/CP \\
\hline WEEE & 0,3716 & 0,3284 & 0,3507 & 0,3297 & 0,3100 \\
\hline RoHS & 0,4263 & 0,3282 & 0,3784 & 0,2648 & 0,1606 \\
\hline PPW & 0,4110 & 0,5313 & 0,4387 & 0,4566 & 0,3310 \\
\hline EMAS & 0,4469 & 0,4116 & 0,4729 & 0,4935 & 0,4183 \\
\hline EPA & 0,3652 & 0,3364 & 0,3558 & 0,3406 & 0,3180 \\
\hline ED & 0,3208 & 0,3576 & 0,3428 & 0,3573 & 0,1857 \\
\hline
\end{tabular}

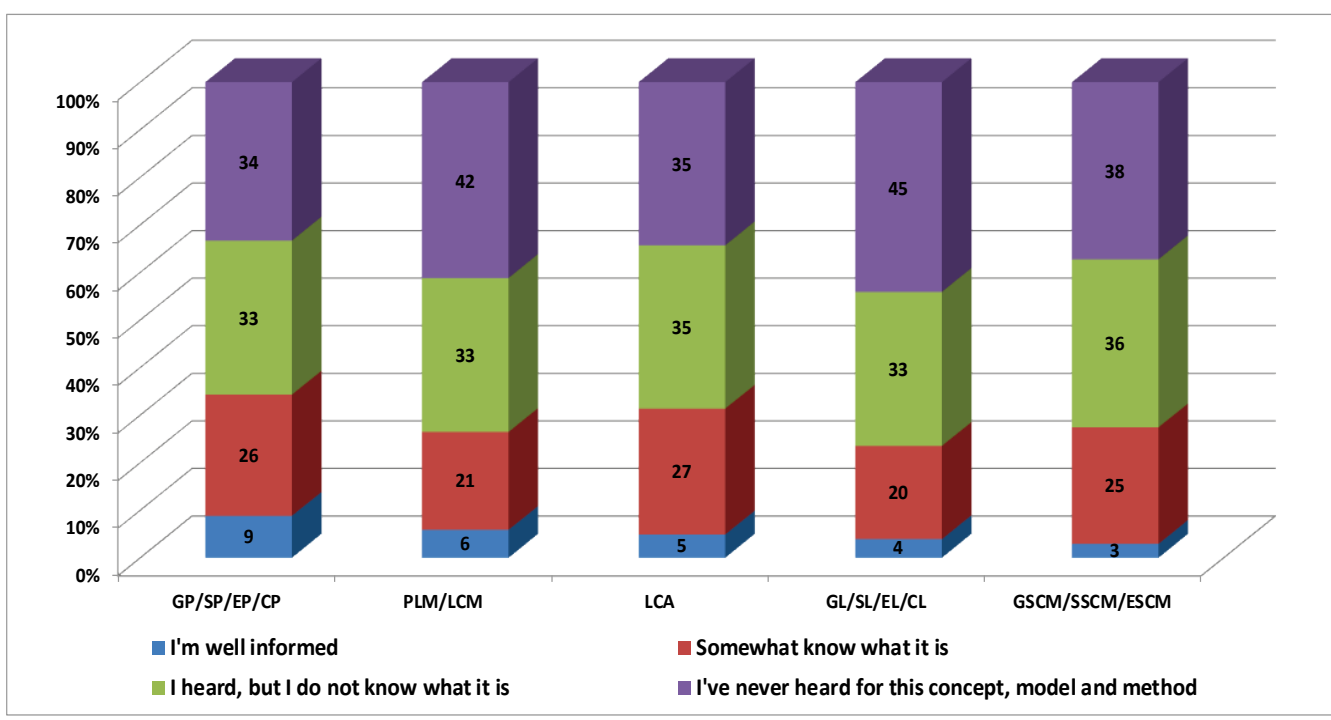

Figure 12 Level of familiarity with the concepts, methods and models

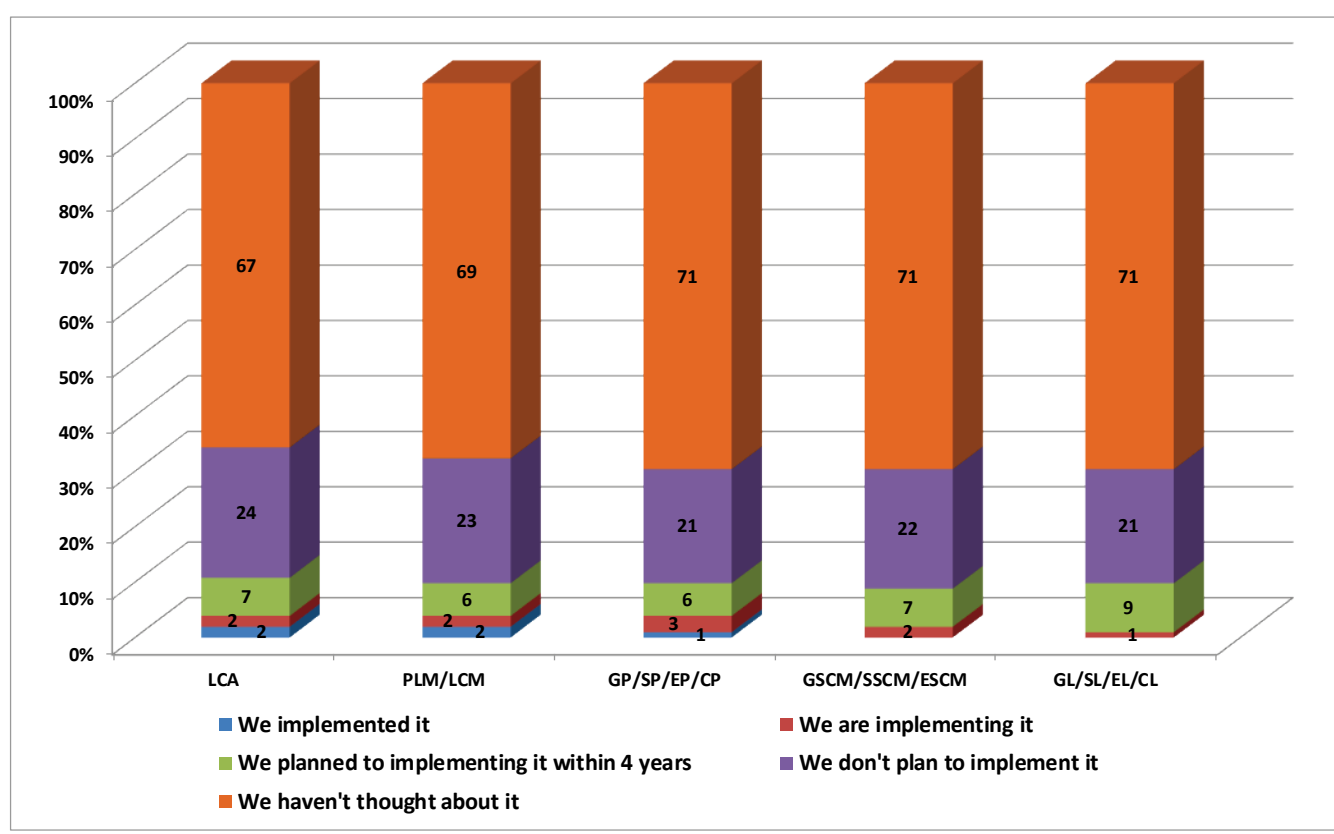

Figure 13 Level of implementation of the concepts, methods and models 


\subsection{Concepts, Methods and Models}

The last section of the second part of the questionnaire shows the level of familiarity with the concepts, methods and models (Fig. 12) while Fig. 13 shows the level of implementation of the concepts, methods and models.

Unlike standards and directives, there is no difference between the level of familiarity between individual concepts, methods and models which is also tested by $\chi^{2}$ test. Very few companies are familiar with the concepts, models and methods mentioned above, and of course even less of them have implemented or are planning to implement some of them. Following the previously formulated thesis, when it comes to environmental impacts we can conclude that Croatian companies mainly implement and apply those standards, directives and laws that are obligated by EU directives, state laws and by suppliers or buyers (standards).

\subsection{Grouping (Clustering) of the Concept, Models, Methods, Standards and Directives}

For clustering purposes it is necessary to find and define the factors that describe the level of implementation of certain standards, directives, concepts, models and methods. This was done by factor analysis which obtained clusters of standards, directives, concepts, models and methods with common dominant factors. Tab. 5 shows the factor analysis of the level of implementation of standards, directives, concepts, models and methods. The groups of factors for the level of familiarity with standards, directives, concepts, models and methods are very similar to those for the level of implementation and because of that they are not presented in the paper.

Strong explanation is considered with individual factors value of more than 0,60 . The factors loadings are presented in Tab. 6. As it can be seen, the level of implementation can be explained through 5 factors.

The table clearly shows groups or clusters of standards, directives, concepts, models and methods. Of course, these groups can be explained by a smaller number of factors. The interpretation of the extracted factors follows.

Thus factor 1 groups together ISO 14040, ISO 14051, ISO 14062, ISO 14064, ISO 26000, ISO 50001 and OHSAS 18001 standards. This factor can be defined as a factor that explains standards whose implementing is not related to suppliers or buyers, but is linked to interest groups within companies (corporate management, trade unions, employees and shareholders) and groups outside the company (investors, insurance companies, ecological associations and groups for environmental protection).

Factor 2 groups the PPW, VOC, EuP, ED and EPA directives and the Environmental Protection Act. This group or factor can be explained as a group of environmental directives and laws that companies implemented or applied in accordance with the EU directives and the law of the Republic of Croatia.

Factor 3 is an interesting factor and authors of this paper define it as a factor within which are the standards that companies implement at the request of suppliers and customers. It grouped ISO 9001 and ISO 14001 standards, which are the standards that are most implemented into Croatian and world companies. These are the standards that suppliers and buyers are looking for the companies to have to prove their quality and environmental care. The correlation analysis was conducted between these two standards and the result shows that there is a strong positive correlation by means of level of implementation $(r=$ $0,4881)$. This suggests that companies that implemented the ISO 9001 standard are likely to implement the ISO 14001 standard in the future.

Table 5 Factor analysis of the level of implementation of the standards, directives concepts, models and methods

\begin{tabular}{|c|c|c|c|c|c|}
\hline Level of implementation & Factor 1 & Factor 2 & Factor 3 & Factor 4 & Factor 5 \\
\hline ISO 9001 & 0,0951 & $-0,0425$ & 0,8141 & 0,0668 & 0,1463 \\
\hline ISO 14001 & 0,3408 & 0,0646 & 0,7761 & 0,1125 & 0,0185 \\
\hline ISO 14040 & 0,8663 & 0,0757 & 0,1133 & 0,2417 & 0,2470 \\
\hline ISO 14051 & 0,8880 & 0,1446 & 0,0997 & 0,2216 & 0,1821 \\
\hline ISO 14062 & 0,9081 & 0,1471 & 0,0755 & 0,0347 & 0,1991 \\
\hline ISO 14064 & 0,8436 & 0,0831 & 0,0388 & 0,0173 & 0,2917 \\
\hline ISO 26000 & 0,7759 & 0,1790 & 0,2218 & 0,0648 & 0,2876 \\
\hline ISO 50001 & 0,8154 & 0,2618 & 0,0723 & $-0,0021$ & 0,2590 \\
\hline OHSAS 18001 & 0,6188 & 0,2293 & 0,4380 & $-0,1688$ & 0,2323 \\
\hline WEEE & 0,1702 & 0,2795 & 0,2354 & 0,6827 & 0,1953 \\
\hline RoHS & 0,0982 & 0,2197 & 0,0205 & 0,8607 & 0,1545 \\
\hline IPP & 0,2554 & 0,4094 & $-0,0553$ & 0,4151 & 0,5902 \\
\hline PPW & 0,1008 & 0,7302 & 0,1074 & 0,1416 & 0,3861 \\
\hline EMAS & 0,1814 & 0,4880 & $-0,0813$ & 0,2834 & 0,4268 \\
\hline VOC & 0,1118 & 0,8311 & $-0,0615$ & 0,2270 & 0,0947 \\
\hline ELV & 0,3761 & 0,3781 & 0,1269 & 0,2428 & 0,3022 \\
\hline EuP & 0,2688 & 0,7469 & 0,1004 & 0,1303 & 0,3733 \\
\hline EPA & 0,2171 & 0,6769 & 0,2589 & $-0,0735$ & 0,2937 \\
\hline ED & 0,2464 & 0,7426 & $-0,1120$ & 0,2601 & 0,1516 \\
\hline LCA & 0,2646 & 0,2742 & 0,1172 & 0,0849 & 0,8292 \\
\hline PLM/LCM & 0,4285 & 0,0913 & 0,0496 & 0,4172 & 0,6577 \\
\hline GL/SL/EL/CL & 0,4149 & 0,2094 & 0,0238 & 0,2922 & 0,7374 \\
\hline GP/SP/EP/CP & 0,3520 & 0,2932 & 0,1098 & 0,0343 & 0,7795 \\
\hline & 0,3515 & 0,1834 & 0,1272 & $-0,0155$ & 0,7355 \\
\hline
\end{tabular}

Factor 4 grouped two directives which, in the opinion of the authors, are the most known directives: the RoHS and WEEE directives. Both Directives directly affect companies because WEEE defines the percentage of produced products that need to be recovered, recycled and 
reused, while RoHS prohibits or defines the amount of harmful substances that may be present in the products. Factor 5 groups GSCM/SSCM/ESCM, PLM/LCM, $\mathrm{GL} / \mathrm{SL} / \mathrm{EL} / \mathrm{CL}, \mathrm{GP} / \mathrm{SP} / \mathrm{EP} / \mathrm{CP}$ and LCA concepts, models and methods. In the opinion of the authors this is not a surprise. This only confirms the author's view that companies do not have a clear picture of the difference between these concepts, models and methods. This clearly shows the high correlations between these concepts, models and methods shown in Tab. 6. For this reason, the systematic view can greatly contribute to the easier understanding of the differences between them, and thus the easier implementation.

Table 6 Table of correlation between the concepts, models and methods regarding the level of implementation

\begin{tabular}{|c|c|c|c|c|}
\hline \multirow{2}{*}{$\begin{array}{c}\text { Level of implementation } \\
\text { of the concept, model and methods }\end{array}$} & \multicolumn{3}{|c|}{ Level of implementation of the concepts, models and methods } \\
\cline { 2 - 5 } GSCM/SSCM/ESCM & PLM/LCM & GL/SL/EL/CL & GP/SP/EP/CP & LCA \\
\hline GSCM/SSCM/ESCM & 1,0000 & 0,8323 & 0,8961 & 0,7414 \\
\hline PLM/LCM & 0,8323 & 1,0000 & 0,7823 \\
\hline GL/SL/EL/CL & 0,8961 & 0,8299 & 1,0000 & 0,7618 \\
\hline GP/SP/EP/CP & 0,7414 & 0,7618 & 0,823 \\
\hline LCA & 0,7823 & 0,9323 & 0,8286 & 0,7688 \\
\hline
\end{tabular}

Finally, the obtained factors can be summarized as described:

- Factor 1 - Influence factor of the interest groups,

- Factor 2 - Influence factor of the EU directives,

- Factor 3 - Influence factor of the supplier and customers,

- Factor 4 - Influence factor of WEEE and RoHS directives (the two most known EU directives),

- Factor 5 - Influence factor of concepts, models and methods.

There are directives where no factor is explicitly defined. These are IPP, EMAS and ELV directives. This means that no factor is dominant and that each factor describes the above standards and directives in small amount. As such, they can be set in a separate cluster, which groups directives that have the same effect of all factors. Therefore, their implementation or application within a company equally affects all of the above defined factors.

\section{CONCLUSION}

As mentioned in the first part of the paper, the PLM, PLCM, LCM, LCA and GSM appear in lots of scientific works. Mostly the papers are related to analysis and interpretation of the above-mentioned concepts, methods and models. The main scope of this paper is to analyse the interrelations between concepts, methods and models. The similarities and significant differences were presented in the second part of the paper which has never been presented before in that way.

Furthermore, the upcoming research should be based on connection between standards and EU directives. This is necessary for understanding the perception of end users and, consequently, trends in the field of the sustainable development. This link could be made as a flow chart that can guide and facilitate the implementation of the above mentioned concepts, methods, models, standards and EU directives

Second part of the paper presents the survey which is carried out in Croatia business sector in view of current state and trends of sustainability. As expected, companies are most familiar with ISO 9001, ISO 14001, OHSAS 18001, WEEE and RoHS standards and directive. Also, these standards and directive are the ones which are most implemented into the company. On the other hand, companies are equally familiar and equally implement (implemented) all concepts, methods and models that are connected with sustainability.

The scope of further research is to determine the characteristics such as knowledge and readiness of the implementation of specific standards and directives regarding the size and business type of the companies. This then can help to find and to determine the decision-making model for implementation of new concept, models, methods, directive and standards.

In addition, for further analysis it is necessary to conduct the same research in other countries inside and outside the European Union. With this analysis we could find out similarities and differences between individual countries, which would lead to a greater understanding of sustainability in the world. This could lead to better and easier implementation of concept, models, methods, directive and standards into the companies.

\section{REFERENCES}

[1] Psomopoulos, C. S., Skoula, I., Karras C., Chatzimpiros, A., \& Chionidis, M. (2010). Electricity savings and $\mathrm{CO}_{2}$ emissions reduction in buildings sector: How important the network losses are in the calculation? Energy, 35(1), 485490. https://doi.org/10.1016/j.energy.2009.10.016

[2] Houghton, J. T., Jenkins, G. J., \& Ephraums, J. J. (1990). Climate change, the IPCC scientific assessment, Cambridge: Cambridge University Press.

[3] Liu, C. C. (2007). An extended method for key factors in reducing $\mathrm{CO}_{2}$ emissions. Applied Mathematics and Computation, 189(1), 440-51. https://doi.org/10.1016/j.amc.2006.09.141

[4] Doha amendment to the Kyoto Protocol to the United Nations Framework Convention on Climate Change. http://unfccc.int/kyoto_protocol/doha_amendment/items/73 62.php. (19.03.2014)

[5] Srivastara, S. K. (2007). Green Supply-Chain Management: A State-of-The-Art Literature Review. International Journal of Management Reviews, 9(1), 53-80. https://doi.org/10.1111/j.1468-2370.2007.00202.x

[6] Bacallan, J. J. (2000). Greening the supply chains. Business and Environment, 6(5), 11-12.

[7] Opetuk, T. (2016). Model of Green supply chain management implementation, Doctoral thesis, University of Zagreb, Faculty of Mechanical Engineering and Naval Architecture.

[8] Opetuk, T. \& Đukić, G. (2014). Literature Survey of GSCM With Interrelated Concepts. Acta Technica CorviniensisBulletin of Engineering, 1, 77-90. 
[9] Bai, C. \& Sarkis, J. (2010). Integrating sustainability into supplier selection with grey system and rough set methodologies. International Journal of Production Economics, 124(1), 252-264 https://doi.org/10.1016/j.jpe.2009.11.023

[10] Chen, C. C., Shih, H. S., Shjur, H. J., \& Wuc, K. S. (2012). A business strategy selection of green supply chain management via an analytic network process. Computers and Mathematics with Applications, 64(8), 2544-2557. https://doi.org/10.1016/j.camwa.2012.06.013

[11] Despeisse, M., Ball, P. D., Evans, S., \& Levers, A. (2012). Industrial ecology at factory level - A conceptual model. Journal of Cleaner Production, 31(10), 30-39. https://doi.org/10.1016/j.jclepro.2012.02.027

[12] Duflou, J. R., Sutherland, J. W., Dornfeld, D., Herrmann, C., Jeswiet, J., Kara, S., Hauschild, M., \& Kellens, K. (2012). Towards energy and resource efficient manufacturing: A processes and systems approach. CIRP Annals Manufacturing Technology, 61(2), 587-609. https://doi.org/10.1016/j.cirp.2012.05.002

[13] Hassini, E., Surti, C., \& Searcy, C. (2012). A literature review and a case study of sustainable supply chains with a focus on metrics. International Journal of Production Economics, 140(1), 69-82. https://doi.org/10.1016/j.jpe.2012.01.042

[14] Pigosso, C. A. D., Zanette, T. E., Filho, A. G., Ometto, R., A., \& Rozenfeld, H. (2010). Ecodesign methods focused on remanufacturing. Journal of Cleaner Production, 18(1), 2131. https://doi.org/10.1016/j.jclepro.2009.09.005

[15] Seuring, S. (2013). A review of modeling approaches for sustainable supply chain management. Decision Support Systems, 54(4), 1513-1520. https://doi.org/10.1016/j.dss.2012.05.053

[16] Seuring, S. (2004). Industrial ecology, life cycles, supply chains: differences and interrelations. Business Strategy and the Environment, 13(5). 306-319. https://doi.org/10.1002/bse.418

[17] Sarkis. J. (2012). A Boundaries and Flows Perspective of Green Supply Chain Management. Supply Chain Management, 17(2), 202-216. https://doi.org/10.1108/13598541211212924

[18] Hollos, D., Blome, C., \& Foerstl, K. (2012). Does sustainable supplier co-operation affect performance? Examining implications for the triple bottom line. International Journal of Production Research, 50(11), 29682986. https://doi.org/10.1080/00207543.2011.582184

[19] Mollenkopf, D., Stolze, H., Tate, W. L., \& Ueltschy, M. (2010). Green, lean, and global supply chains. International Journal of Physical Distribution and Logistics Management, 40(1-2), 14-41. https://doi.org/10.1108/09600031011018028

[20] Liu, S., Leat, M., \& Smith, M. H. (2011). State-of-the-art sustainability analysis methodologies for efficient decision support in green production operations. International Journal of Sustainable Engineering, 4(3), 236-250. https://doi.org/10.1080/19397038.2011.574744

[21] Bi, Z. (2011). Revisiting System Paradigms from the Viewpoint of Manufacturing Sustainability. Sustainability, 3(9), 1323-1340. https://doi.org/10.3390/su3091323

[22] Shan-Ping, C. \& Chang-Lin, Y. (2014). Key success factors when implementing a green manufacturing system. Production Planning \& Control: The Management of Operations, 25(11), 923-937. https://doi.org/10.1080/09537287.2013.780314

[23] Govindan, K., Soleimani, H., \& Kannan, D. (2014). Reverse logistics and closed-loop supply chain: A comprehensive review to explore the future. European Journal of Operational Research, 240(3), 603-626. https://doi.org/10.1016/j.ejor.2014.07.012

[24] Devika，K., Jafarian, A., \& Nourbakhsh, V. (2014). Designing a sustainable closed-loop supply chain network based on triple bottom line approach: A comparison of metaheuristics hybridization techniques. European Journal of Operational Research, 235(3), 594-615. https://doi.org/10.1016/j.ejor.2013.12.032

[25] Leigh, M. \& Li, X. (2015). Industrial ecology, industrial symbiosis and supply chain environmental sustainability: a case study of a large UK distributor. Journal of Cleaner Production, 106, 632-643. https://doi.org/10.1016/j.jclepro.2014.09.022

[26] Kannan, D., de Sousa Jabbour, A. B. L., \& Chiappetta Jabbour, C. J. (2014). Selecting green suppliers based on GSCM practices: Using fuzzy TOPSIS applied to a Brazilian electronics company. European Journal of Operational Research, 233(2), 432-447. https://doi.org/10.1016/j.ejor.2013.07.023

[27] Hauschild, M., Jeswiet, J., \& Alting, L. (2005). From Life Cycle Assessment to Sustainable Production: Status and Perspectives. CIRP Annals - Manufacturing Technology, 54(2), 1-21. https://doi.org/10.1016/S0007-8506(07)60017-1

[28] SolidWorks Sustainable Design Guide, https://www.solidworks.com:80/sustainability/sustainabledesign-guide.htm (24.04.2012)

[29] Jeroen, B. G. (2004). Handbook on Life Cycle Assessment Operational Guide to the ISO Standards. New York, Boston, Dordrecht, London, Moscow: Kluwer Academic Publishers.

[30] Karlsruhe institute of Technology, https://www.imi.kit.edu/ english/209 368.php (24.04.2012)

[31] Chaudhary, K. \& Chandhiok, T. (2011). Product Lifecycle Management Phases of Product Lifecycle and Corresponding Technologies. International Journal of Marketing and Technology, 1(1), 25-36.

[32] Life Cycle Management Business Portal, https://www.epa.vic.gov.au/lifecycle (24.04.2012)

[33] Council of Supply Chain Management Professionals, https://cscmp.org (24.04.2012.)

\section{Contact information}

Tihomir OPETUK, PhD.

University of Zagreb,

Faculty of Mechanical Engineering and Naval Architecture,

Department of Industrial Engineering, Chair of Production Design,

Ivana Lucica 1, 10000 Zagreb, Croatia

Tel. +3851/61 68332

E-mail: thomir.opetuk@fsb.hr

Hrvoje CAJNER, PhD, Assist. Prof.

University of Zagreb,

Faculty of Mechanical Engineering and Naval Architecture,

Department of Industrial Engineering, Chair of Production Control,

Ivana Lucica 1, 10000 Zagreb, Croatia

Tel. +3851/61 68331

E-mail: hrvoje.cajner@fsb.hr

Goran DUKIC, PhD, Prof.

University of Zagreb,

Faculty of Mechanical Engineering and Naval Architecture,

Department of Industrial Engineering, Chair of Production Design,

Ivana Lucica 1, 10000 Zagreb, Croatia

Tel. $+3851 / 6168381$

E-mail: goran.dukic@fsb.hr

Davor KOLAR, mag. ing. mech.

University of Zagreb,

Faculty of Mechanical Engineering and Naval Architecture,

Department of Industrial Engineering, Chair of Production Control,

Ivana Lucica 1, 10000 Zagreb, Croatia

Tel. +385 1/61 68355

E-mail: davor.kolar@fsb.hr 